\title{
Joaquín de Helguero y el pensamiento económico borbónico en Piura a comienzos del siglo XIX
}

\section{RESUMEN}

En este escrito realizamos una lectura global de un manuscrito sobre la economía de Piura de 1802 elaborado por don Joaquín de Helguero. Se presenta y examina la respuesta a un «Cuestionario» remitido por el Consulado de Lima. La información registrada muestra la existencia de un plan que refleja un enfoque metódico y riguroso del funcionamiento de un espacio económico y la vida social y laboral de las gentes que cohabitan en un paisaje dorado de la costa desértica y de las montańas cordilleranas que cruzan el norte del territorio del virreinato del Perú. En este texto se muestra cualitativamente la heterogeneidad de las gentes y la polidiversidad de sus prácticas productivas, también la dispersión y el carácter fragmentario de las economías indígenas, y la diversidad y los límites a los que había llegado un tipo de economía que buscaba transformar las reformas políticas de los Borbones desde mediados del siglo xviII.

Palabras Clave: Piura; economía; Borbones; tierras; haciendas; geografía.

\section{Joaquin de Helguero and bourbon economic thought in Piura during the early 19th century}

\begin{abstract}
In this paper we make a global reading of a manuscript about Piura's 1802 economy, elaborated by Joaquin de Helguero. We present and examine the response to a "Questionnaire» submitted by the Consulate in Lima. The recorded information shows existence of a plan that reflects a methodical and rigorous approach to the functioning of an economic space, social and labor life of people who cohabit in a golden landscape of a coastal desert and mountain ranges crossing the northern territory of the Viceroyalty of Peru. In this text, we qualitatively show the heterogeneity of people and polidiversity of their productive practices, as well as dispersion and fragmentary character of indigenous economies, diversity and limits to which a type of economy had arrived that sought to transform the Political reforms of the Bourbons since mid-eighteenth century.
\end{abstract}

KeYwords: Piura; economy; Bourbon; lands; haciendas; geography.

\footnotetext{
Este ensayo es un segundo capítulo revisado de un proyecto de investigación financiado por el Vicerrectorado de Investigación y Posgrado de la UNMSM,
} Código Nº 16501021, año 2016. 


\section{Introducción}

1. En la historia del pensamiento histórico de Piura y del virreinato del Perú de comienzos del siglo XIX, don Joaquín Helguero es todavía un personaje misterioso sobre sus ideas acerca del tiempo en que le tocó vivir y morir, relatar lo que veía y describir con su pluma las emociones que le provocaban los cambios de la naturaleza y de las gentes que lo rodeaban. Al momento de escribir su «Informe» estaba consciente de que todo tiene su historia, incluso la historia que sobre Piura escribía con mucha paciencia. En su relato podemos encontrar una descripción fabulosa del pasado, pero también un intento de reflexión sobre las motivaciones de las permanencias y los cambios en el paisaje natural $\mathrm{y}$ las sensibilidades de los criollos, los indígenas y afrodescendientes. En este escrito se encuentra no solo la descripción de los acontecimientos del pasado, sino también una propuesta de estudio y descripción de este pasado que lo angustia, pues la mayoritaria población indígena marchaba contra la corriente moderna de articularse al mercado y a la civilización eurooccidental. Es por esta doble entrada y de reflexión de la historia que su pluma e ideas llamaron mucho la atención de Bruno Revesz Long y de Pablo Macera para su difusión artesanal en el Seminario de Historia Rural Andina de la UNMSM, en el último tercio del siglo xx.

Se unieron entonces dos vocaciones de las ciencias sociales, el primero, Pablo Macera que maduraba el presente y futuro de la profesión de la Historia y del historiador, y el segundo, Bruno Revesz, jesuita y sociólogo francés, quien se había introducido a profundidad en su proyecto de describir y reflexionar acerca de la marcha y dinámica de la economía y la sociedad privilegiando el examen del campesinado indígena de Catacaos y el desafío milenario de los tallanes y guayacundos piuranos. ${ }^{1}$

Ambos personajes experimentaron sus vidas para la tarea de la enseñanza y la escritura de la historia como una profesión acreditada desplegando un enorme esfuerzo para sumar el relato y la escritura del pasado que permitiera impulsar cambios en el presente que

1 Miguel Pinto ha recopilado y actualizado las investigaciones y reflexiones de Pablo Macera sobre el Perú andino y contemporáneo (Pinto 2014 y 2015). Bruno Revesz publicó muchos artículos de síntesis acerca de la historia regional y proyectos de investigación sobre Piura en el CIPCA, IEP y en la Universidad del Pacífico. Véase: Bruno Revesz (2013) y Bruno Revesz y Julio Oliden (2011). También puede consultarse el Tesaurus bibliográfico de Piura en Bruno Revesz; Susana Aldana; Laura Hurtado y Jorge Requena (1997). vivían. Se trataba de un ejercicio consciente que sumaba el contenido de la palabra historia con la investigación. Cada uno realizó su proyecto personal e institucional para organizar primero un centro de documentación que les permitiera registrar y escribir sucesos reales sobre la gente y su vida cotidiana acompañado de ensayos y reflexiones sobre sucesos milenarios de los Yngas y los Tallanes. En la tarea que asumieron, ambos, como lo hizo Helguera en su tiempo, se dedicaron a llevar el registro de determinados sucesos y de personas que influían en la marcha de la historia para finalmente esbozar el nacimiento de una conciencia histórica, de los cambios ocurridos en la mentalidad y el vocabulario usando el complicado método científico y revisando incluso el debate provocado por el materialismo histórico y la temática de los modos de producción para la construcción y revisión de lo que ahora se llama el nacionalismo andino moderno. ${ }^{2}$

2. El texto que publican Pablo Macera y Bruno Revesz con un prólogo de Nadia Carnero corresponde a un informe realizado por el diputado del comercio de la provincia de Piura, don Joaquín de Helguero Gorgolla, un personaje notable y de mucho prestigio social en la ciudad de San Miguel de Piura a comienzos del siglo XIX. El documento de 1802 es una respuesta escrita a una demanda que contiene un cuestionario enviado desde la ciudad de Lima por los funcionarios del Tribunal del Consulado que se muestran preocupados por las finanzas virreinales que deben manejar las autoridades reales para enfrentar al enemigo británico que acosaba las orillas del mar y las costas del Pacífico Sur. ${ }^{3}$

Una lectura global del manuscrito transcrito muestra la existencia de un plan que refleja un enfoque metódico y riguroso del sujeto a describir, un espacio

2 Burga 1993: 80-96. Piura es una región de debate historiográfico permanente. Una síntesis de la historia global se encuentra en el trabajo de Anne-Marie Hocquenghem (1998) y desde la microhistoria y la demografía de los pueblos costeńos y serranos en Huertas (1997). En esta empresa de reflexión y análisis, de la difusión de documentos inéditos y la reedición de textos antiguos destacan German Leguía y Martínez (1914), Pablo Macera (2014); Arturo Jiménez Borja e Irma Franke (2007); Alejandro Reyes Flores (1999); Jorge Eduardo Moscol Urbina (1986 y 1991); Miguel Maticorena (1994); Miguel Arturo Seminario (1995); Félix J. López (2007), Claude Collin Delavaud (1984) y Raúl Estuardo Cornejo (2007).

3 El Seminario de Historia Rural Andina (SHRA-UNMSM) y el Centro de Investigación y Promoción del Campesinado (CIPCA-Piura) publicaron el Informe económico de Piura, 1802 de Joaquín de Helguero (1984). Transcrito y presentado por Nadia Carnero. Colección Historia Piurana, No 1, Edic. Cipca, SHRA, UNMSM, Piura, Perú. Sobre la geografía y la economía regional de Piura, Pablo Macera publicó un texto inédito en la Revista del Archivo Nacional del Perú (1964). 
económico y la vida social y laboral de las gentes que cohabitan un paisaje dorado de la costa desértica y de las montañas cordilleranas que cruzan esta parte del territorio del virreinato del Perú. Mi lectura es una propuesta de trabajo que puede servir de marco metodológico a otros investigadores que desearían examinar una temática similar en otras regiones de los Andes del Perú.

En este texto se encuentra registrada la heterogeneidad de las gentes y la polidiversidad de sus prácticas productivas, también la dispersión y el carácter fragmentario de las economías indígenas, y la diversidad y los límites a las que había llegado un tipo de economía que buscaban transformar las reformas políticas de los Borbones desde mediados del siglo XviII. ${ }^{4}$

En este escrito de Helguero encontramos la asociación y presentación del marco natural con las características geográficas por valles (costa y sierra), cruzado por una hidrografía cuyos afluentes y ríos van a desembocar en Sechura y San Lucas de Colán registrando una variedad de especies de peces y su procesamiento para la alimentación y comercio a otras ciudades del virreinato del Perú. Helguero ofrece y analiza algunas técnicas empleadas para el procesamiento de los productos marinos, pero también de plantas y animales mayores y menores. Le interesa en particular, medir los volúmenes de producción orientados hacia el mercado y reflexiona con apuntes al vuelo sobre la cuestión de su impacto en el entorno regional y las costumbres de los pueblos indígenas y las reglamentaciones existentes para su fluidez económica. ${ }^{5}$

En efecto, cuando examina la producción de las haciendas y estancias ganaderas busca precisar los ciclos de crecimiento y de disminución en correspondencia con las estaciones climáticas y el movimiento de los precios. Revisa las formas productivas y los modos de explotación de las tierras y los bosques de algarrobo, las formas de arrendamiento y conducción de la tierra y la multiplicación de los propietarios rurales registrando

4 La geografía y los recursos humanos de Piura han sido temas profundizados por un conjunto de investigadores franceses que van desde Claude Collin Delavaud (1984) hasta Anne Marie Hocquenghem, pero también han sido analizados por Hildegardo Córdova, Alejandro Reyes, Susana Aldana, Alex Diez Hurtado (1998) y Elizabeth Hernández García (2008 y 2011). Vicente Santuc, Bruno Revesz y Francisco Mugguiro impulsaron en el CIPCA uno de los centros documentales y de información regionales más importantes del Perú en el último tercio del siglo xx.

5 Macera 2014: 324-343. César Espinoza también ha reconstruido el paisaje geográfico de la sierra y la costa de Piura. Véase: Espinoza C. $(2005,2008$ y 2013). la multiplicación de pequeños poseedores y de grandes señores de la tierra, y sus vinculaciones con las tierras de ejidos que administra la ciudad de SM de Piura, la persistencia de los señores laicos, las instituciones eclesiásticas y comunidades articuladas a un pequeño mercado interno regional e interregional.

La pluma de Helguero describe la existencia estructural de muchos conflictos inevitables existentes en los valles de Piura, La Chira y en las cordilleras de Ayabaca, Guancabamba y Guarmaca. En la respuesta a las preguntas que se le encarga responder registra aspectos técnicos vinculados a la labranza de la tierra, a la crianza del ganado caprino, vacuno y mular, pero también apunta algunas notas interesantes sobre la situación que viven los hombres que practican la labranza de la tierra y buscan una renta y una ganancia semestral y anual. De tal forma que en su exposición encontramos ideas y datos sobre los hacendados, los labradores campesinos, indígenas, mestizos y negros esclavos y libertos, pero también sobre los pescadores e intermediarios (mercaderes y regatones) que compran y realizan negocios con otras gentes de Loja y Cuenca por el norte, y Lambayeque, Trujillo y Lima por el sur del Perú.

Helguero es un noble ilustrado que busca mostrar los procesos de comercialización de los productos de la tierra (granos y frutales, tubérculos y panllevar, algodón y trigo, cascarilla y caña de azúcar) desde y fuera de la ciudad de SM de Piura, sin olvidar que esta actividad mercantil está sometida a una abundante y puntillosa reglamentación municipal y virreinal. No olvida señalar que se trata de mercancías que están bajo un sistema de contribuciones y que la circulación también está vigilada por los regidores en lo que se refiere a precios y medidas. Sin embargo, es muy escueto en describir la historia y el funcionamiento de las tinas de jabón y las fábricas de cordobanes ubicados en el centro de la ciudad, pero también en las orillas del río Piura. De igual forma, escasean los datos sobre los molinos, y la oferta de alimentos y productos frescos y salados.

Falta una mayor descripción sobre las tierras cultivadas y labradas con el algodón en Tangarará, y de los afluentes de los ríos que desembocan y abastecen al Piura y La Chira. Usando los procesos judiciales, civiles y criminales se podría completar la geografía regional y una mayor ilustración de las estancias y las economías indígenas regionales, los circuitos de distribución cortos y de larga distancia, conocer las zonas de pesca entre 
Colán y Tumbes, o la movilización de balsas y botes cargando la brea y el agua dulce hacia el puerto de Paita.

En la descripción que realiza Helguero de los diversos rubros que ofrece la economía regional de Piura, se busca presentar la producción y la transformación de los cultivos, pero también lo que oferta la estancia ganadera y los pueblos indígenas asentados en las orillas y desembocaduras de los ríos. Por tanto, Helguero oferta una visión y pensamiento de la economía regional de Piura en su tiempo, el funcionamiento de una economía heterogénea, pinceladas breves sobre las técnicas usadas, los alimentos para el consumo o la alimentación, y lo que oferta en un tiempo de crisis económica y de guerra contra Gran Bretańa, sumando la idea de la falta de correspondencia a la fuerza del mercado por las economías indígenas cuyas gentes son acusadas de vivir en el "ocio y en el vicio», por no escribir, pues se trataba de una modalidad singular de resistencia social de los pueblos a la presencia de España en Piura. ${ }^{6}$

3. En esta ocasión entregamos la exposición, análisis y reflexión de las ideas expuestas por don Joaquín de Helguero y Gorgoya en 1802, que resume la respuesta a un cuestionario enviado por el Consulado de Lima, y en la que encontramos una primera visión sistemática de la dinámica e historia de la economía regional de Piura luego del brutal impacto del FEN de 1791 en toda la costa y los Andes del Perú. ${ }^{7}$

El texto que ahora trabajamos asume diversas formas de análisis y exposición. En algunos casos, primero incluimos la pregunta y luego los datos y la información cuantitativa y cualitativa que ingresa. Es sobre esta base documental que yo me permito incluir algunos apuntes sostenidos y fundamentados en la información recogida en los archivos notariales de la época para acercarnos a la reconstrucción de una

6 Santiago Castro-Gómez (2005). Sobre las visiones y metodologías en el campo de la historia he consultado a Eulalia Ribera Carbó (2005), Milton Santos (2004) y a Holt Jensen (1992).

7 Don Joaquín de Helguero y Gorgoya murió en 22 de agosto de 1830, en el sitio y monte de la Rinconada, La Huaca, un pueblo ubicado al otro lado y en la parte terminal del río La Chira, frente al poblado de Amotape. Sus padres fueron Francisco Antonio de Helguero y Serna y María Teresa de Gorgoya y Rivero. Se casó con Juana Josefa de Carrión e Iglesia. Para recuperar su dote de cerca de 50 mil pesos, prosiguió un prolongado juicio ya que solo tenía una carta poder (31/07/1820) legalizada por don Miguel de Armestar, alcalde ordinario y justicia mayor de Piura. En este proceso judicial actuaron como defensor testamentario, don Mariano del Valle, y en calidad de contador y divisor de bienes, don Santiago Távara y Andrade (Archivo Regional de Piura, Notario Manuel Rebolledo, Legajo 10, año 1830, folios 120-123). página de la historia económica de Piura a comienzos del siglo XIX.

Sección Punto Dos. "Producciones de toda clase que se cosechan en este territorio con designación prudente del monto anual de cada una».

En el Punto 1, Helguero expone sus ideas económicas sobre la «calidad y naturaleza del terreno y el estado de su comercio» en Piura a comienzos del siglo XIx. En esta segunda sección trabaja un conjunto de proposiciones sobre lo que él entiende acerca de las bases de una economía regional en un estado de crisis (para esta calificación usa el concepto de "deterioro») permanente como consecuencia de la «variedad de los tiempos pasados, y anuncio probable de los venideros». Helguero explora e intenta construir una explicación racional del presente que vive utilizando una variedad de imágenes que esboza sobre la historia y la evolución de la economía para postular lo que podría devenir en adelante. En esta dirección, confiesa que encuentra muchas dificultades para fijar y calcular un monto anual para cada especie producida y comercializada en la provincia de Piura. En el tiempo inmediato que vive, la vida social atraviesa un tiempo de crisis económica de larga duración, y afirma categóricamente que no encuentra datos y una visión de esperanza de que se pueda producir un cambio en el corto plazo.

Helguero quiere y propone salir de esta vida económica decadente y combate su propia expresión de desánimo y de escepticismo proponiendo una «prudente regulación» del número anual de los flujos de las producciones y las cosechas en un territorio geográfico complejo (Helguero 1802, 53) del norte del virreinato del Perú. De tal forma que al abordar el «Punto Uno» expone las subidas y las caídas del comercio regional divididas en dos espacios ecológicos (los valles y la sierra) con sus producciones de vegetales y animales. De tal forma que concluye que la parte de la sierra se ha especializado en la producción de mulas, yeguas, vacuno, ovejuna y cría de puercos. Es decir, al interior de la provincia de Piura se ha conformado un espacio ganadero heterogéneo, de crianza masiva y no de calidad, y que, sin embargo, se trata de una actividad pecuaria que genera un "producto copioso y una considerable entrada de dinero por este ramo». Agrega a esta tesis, que en los territorios de Ayabaca y Guarmaca se han especializado en la producción de toda clase de ganados y también en la producción y la cosecha del trigo. Por el contrario, en el espacio que 
él denomina los «valles» (la costa), verifica que aquí la ganadería se ha reducido a la cría del ganado mular y vacuno; y que a esto se suma la vida ganadera de las haciendas que asumieron la forma de estancia ganadera dedicada a la crianza masiva del ganado cabrío, conduciendo manadas de mil cabezas que luego van a servir de ganado de matanza usado como materia prima para la fabricación de jabones y cordobanes.

Helguero se explaya en analizar la dinámica de la ganadería regional. Postula la tesis de que el número de cabezas de este tipo de ganado caprino crece mucho más cuando se vive un tiempo de lluvias (aguaceros) y se contrae/reduce en los tiempos de sequía (años secos). Encuentra entonces una regularidad natural asociada al movimiento de la economía local, es decir, una relación directa entre el impacto de los ciclos climáticos con los ciclos productivos ganaderos regionales. Y, es a partir de esta correlación comparativa que encuentra evidencias de que la caída o el alejamiento de las aguas (sequedad) permitirá la reproducción/aumento o contracción/ disminución de los ciclos productivos, y el movimiento hacia arriba o hacia abajo de los precios de este tipo de ganado menor. En efecto, bajo esta proposición plantea que en tiempos de la abundancia de pastos, el precio por cabeza se reducirá a 8,10 y 12 reales, y cuando escasea o se prolonga la sequía, el precio subirá a $1 \frac{1}{2}$ pesos. Helguero expresa finalmente, que el precio de esta mercancía estará atado a los ciclos de la esterilidad o fecundidad de los pastos. En buena cuenta, usando los indicadores socioambientales, Helguero especula y calcula que en cada año se benefician entre 25 a 30 manadas (de mil cabezas c/u).

Otro tipo de producción económica que examina Helguero es la que se registra en el espacio territorial denominado de los «valles». Se trata de la agricultura de la producción y la cosecha del algodón en rama y su manufactura bajo la forma de pabilo, costales y lona labrados y tejidos por las manos y los pies de los campesinos indígenas. Sobre este asunto de la intervención de la mano de obra se muestra muy recatado y lo que practica es el ocultamiento y silenciamiento de los labradores rurales y de la gente indígena que se ha especializado en la práctica de un tipo de tierras de cultivo y en la manufactura artesanal, que en su mayoría se encuentra dispersa en las tierras y las parcialidades de Catacaos, Colán, Sechura y Olmos. Tampoco dice nada de otro grupo poblacional menor que se encuentra establecido y está organizado en las cofradías de artesanos y que dinamiza la vida en los barrios periféricos de la ciudad de SM de Piura. Sin embargo, lo interesante de la reflexión de Helguero es que, en este caso, los volúmenes del algodón en rama también dependerán de los ciclos de las lluvias y sequías para ampliar las fajas de «tierras húmedas» en las orillas y desembocaduras de los ríos. En buena cuenta, no le queda esta vez sino confesar que carecía de la información suficiente para estimar un cálculo del producto anual total y repite un conjunto de datos y series numéricas generales expuestos en la Sección Punto Uno (Helguero 1802, 55-56). ${ }^{8}$

\section{Tercer Punto. «Precios corrientes de estas producciones, $y$ demás objetos comerciables de la provincia».}

Sobre este asunto de la producción, los precios y el mercadeo local, Helguero utiliza una serie de variables e indicadores tratando de proporcionar una imagen global de lo existente en la provincia de Piura. Así, divide el espacio geográfico entre sierra y valles, y nuevamente presenta datos sobre la producción de granos, tipo de ganados, trapiches, algodón en rama, hilados y tejidos en calidad de indicadores que se cosechan semestral y anualmente en un espacio geográfico natural y diverso que contienen terrenos que disponen o no de agua y de una red múltiples de canales de riego. En su exposición incluye otras variables para poder verificar el peso de cada tipo de cosecha, la variación de los tiempos (tiempo húmedo y tiempo seco) para estimar la producción y calcular la producción y un monto anual en pesos. Para este efecto, utiliza las categorías de "precio corriente y justiprecio", y el valor de cada producto.

Respecto a la marcha de la economía en los valles, plantea que los hacendados y los colonos conductores de grandes parcelas, sufrirán el impacto de muchas calamidades del tiempo climático; para esta fecha considera que casi todos sufren la calamidad de los tiempos de la sequía, en la que la tierra se endurece y predomina el polvo, y en consecuencia crece imparablemente la mortandad del ganado por la falta de agua y de pastos; se vive, entonces, un ciclo de crisis

8 Los datos de la economía campesina indígena se pueden encontrar de manera dispersa y puntual en los expedientes sobre procesos judiciales por la posesión y delimitación de fronteras de tierras y en los testamentos de propietarios que se disputan por lotes de tierras y de mano de obra negra esclava e indígena. De igual forma, también se registran datos en los inventarios de tierras parcelarias alquiladas y de arrentadarios ubicadas en el piedemonte andino como Tambogrande, Yapatera y Morropón. Véase: Archivo Regional de Piura, Sección Protocolos Notariales. Piura. 1825-1854. Cabildos, Gobernaciones y Jueces de Paz. Pablo Macera (2000) ha compilado otro tipo de información sobre la geografía ubicada en el archivo del Congreso del Perú. 
con una alta mortalidad de los animales reduciéndose los capitales de los propietarios y de los campesinos colonos mestizos e indígenas.

Sobre el ganado cabrio explica que una manada está compuesta de mil cabezas, y que su precio oscilaría, por cada cabeza, entre $3 \frac{1}{2}$ pesos (28 reales) a 4 pesos (32 reales). Calcula que en una manada subsistían estratos de cabras y chivatos gordos y flacos, y que estos también se diferenciaban por la edad para cada cabeza. Finalmente, Helguero estima que en esta ocasión el precio dominante del ganado en tiempos de sequía es de 28 reales.

A continuación, agrega sobre este asunto, que, en tiempos de lluvias, el ganado vacuno alcanza su precio por cada cabeza de res, un valor que se mueve entre 13 a 15 pesos; por el contrario, en las temporadas de sequias y escasez de aguas y de pastos, el precio oscilaría entre 20, 24 y 26 pesos. De esta forma, reitera su tesis de que el hacendado de la costa no fomenta la crianza y el engorde de los vacunos sino la de las cabras. Y, que lo mismo ocurría con la crianza del ganado mular, muy escaso en los «valles», y que en esta se reducía su producción solamente a dos y tres grandes haciendas rurales.

Ahora bien, sobre este tipo de ganado, Helguero afirma que la mula registra un precio casi permanente, estable, y que solo se mueve, hacia arriba o hacia abajo, motivado por las urgencias que vive el vendedor, las cualidades de la mula, y que este animal sería usado como bestia de silla o de tiro de calesa. Por tanto, señala que es común que su precio oscile de 26,28 a 30 pesos. Agrega, de manera particular, que el precio de una mula para tirar una calesa ascendería a 100 pesos (Helguero 1984, 58-59). Uno de los grandes propietarios de tierras en Piura es don Fernando Seminario y Jayme, un notable criollo que goza para movilizarse por los caminos de la provincia de una calesa jalada por mulas de diversos colores y pelajes, tratando de ganarle la velocidad al tiempo que le tocó vivir.

Otro tipo de labranza vegetal que se practica en esta provincia es el cultivo del algodón, una planta que se cosecha en las tierras húmedas existentes en ambas franjas del valle de La Chira (que denomina el «otro río»), pero también en las inmediaciones de la ciudad de SM de Piura y en el valle y a orillas del río que pasa por el pueblo de Catacaos y alrededores. En esta ocasión, Helguero calcula un volumen total de la cosecha anual entre 17 y 18 mil quintales en los ańos buenos, y de 8 a 9 mil quintales en los años secos. De igual forma, los precios también varían según el impacto de los ciclos de las alteraciones climáticas, entre 7, 9 a 10 pesos en los primeros, y de 18,19 y 20 pesos en el segundo, o años secos.

Helguero es un hombre cristiano e ilustrado; vive en una casa-mansión en la ciudad de SM de Piura, pero también permanece unas largas temporadas en sus tierras vecinas en el sitio de El Arenal. Se trata de un criollo ilustrado que utiliza la escritura no solo para contar números sino también para apuntar detalles interesantes sobre su propia vida y la de las gentes que lo rodean. Para su tiempo podemos decir que se trata de una persona eurocivilizada que busca la felicidad de su pueblo sometido a Dios y a las leyes dictadas por el rey de Espańa. En su visión sobre la economía razonada presenta a los otros agentes económicos bajo la categoría de "gentes miserables», repetirá de esta forma la mirada colonial, eurocentrista y discriminatoria que dominaba el pensamiento criollo e hispano. En efecto, los «otros» son vistos como gente bárbara, sin educación y propensos a la resistencia y rebeldía social. En su escrito que examinamos se refleja su miedo a la existencia de otra sociedad y de gentes que puedan vivir y reproducirse practicando otro tipo de economía no sujeta a la lógica del mercado y sí a los principios sociales de la reciprocidad y del colectivismo comunitario.

Otros escritos como los informes de Lequanda y Martínez de Compañón, muestran que la gran mayoría poblacional está organizada en pueblos y comunidades indígenas que laboran la tierra; son los campesinos parcelarios indígenas y tributarios, y que también subsistía otro sector de trabajadores rurales como los colonos subarrendatarios, criollos, mestizos y afrodescendientes que laboraban al interior de las grandes propiedades rurales.' Sobre este asunto, Helguero se limitará a señalar que el algodón producido y cosechado en capullo (en rama) lo procesan estas gentes para transformarlos, usando no solo las manos sino también una diversidad de herramientas y tiempo, que olvida registrarlos, en pabilos y tejidos que son

9 Lequanda 1793: 167-229. Martínez de Compañón (1978 [1784]). Miguel Jaramillo Baanante (1998) ha trabajo el tema de los precios y los salarios en la región de Piura para luego ensayar una propuesta de los ciclos económicos construyendo tablas y reflexiones interesantes. Y, desde una perspectiva microregional, también Carlos Gálvez Peña (1998) se ha introducido a examinar la economía de la cascarilla que producían las montańas amazónicas de Piura y Loja. De igual forma, la monografía de Bernardino Ferrante y Horacio Correa (1997) proporcionan datos del archivo local de Huarmaca para comprender los lazos económicos con Lambayeque y Saña. 
usados bajo la forma de costales y pitas, para luego transportarlos bajo la categoría de materias primas al mercado local y regional.

Respecto al cultivo del algodón, Helguero calcula que, en tiempo de abundancia, se consume en la ciudad entre 4 a 6 mil quintales en libras de pabilo a un precio de $1,1 \frac{1}{2}$, y 2 reales. Se trata entonces de un tipo de manufactura textil artesanal que muestra la existencia de un movimiento de la demanda dentro y fuera de la provincia de Piura.

De otra parte, Helguero agrega algunos apuntes sobre el funcionamiento de otro tipo de manufactura textil que utilizaría una gran cantidad de algodón para la producción de los costales y las lonas, los cuales son remitidos a la ciudad de Piura y fuera de la provincia. Estima, por tanto, que el valor de un costal llegaría hasta los $5 \frac{1}{2}$ reales, y una vara de lona a $1 \frac{1 / 4}{\mathrm{real}}$, en los ańos fecundos, y a 5 reales y $1 \frac{1}{2}$ real en los tiempos escasos de agua.

Helguero recuerda la existencia y la dinámica de otros tipos de «renglones» económicos que giran en la provincia pero que en ese momento solo mantienen una oferta escasa y se encuentran «abatidos», y que solo generan una "ridícula entrada» monetaria. En efecto, se trata de varios objetos que denomina «comerciables» pero que no se promueven porque los productores de esta provincia se encuentran dominados por un tipo de conducta que califica de "desidia y malicia», y que son practicados por sus gentes con escaso interés para su distribución y venta.

Otra forma y tipo de producción que le llama la atención y lo anota es la que se extrae del mar por la gente que vive en los pueblos y las orillas de manera dispersa. En efecto, en los puertos de Sechura y Paita abunda la pesca del tollo, el marrajo, el peje salado y la raya. Helguero resalta en particular, las dos últimas especies que abundan en Paita. El peje salado y el tollo registran mucha demanda desde las ciudades de Lima, Trujillo y Piura. En su apunte destaca la calidad, la frescura y el buen gusto de sus carnes que se consumen en los pueblos rurales y las campiñas de la costa y la sierra de Piura. Helguero tiene noticias sobre la abundancia de muchas clases de peces marinos, pero también de que las poblaciones indígenas muestran poco interés en incrementar su expendio y comercio para el lucro.

La historia y vida de las poblaciones yungas muestran la conservación de sus rutas comerciales utilizando la fuerza de las corrientes marinas a lo largo del Mar del Sur; así, por el norte, utilizan sus embarcaciones de madera y de totora (balsas) para trasladarse a Guayaquil y a Paita. Por el sur llegan a Huacho y a Chorrillos (Marcavilca y La Chira). Se trata de pueblos yungas tallanes que transportan sus producciones para intercambiarlos y sostener sus pequeńos caseríos estacionales según el movimiento de los ciclos climáticos y la fuerza de las corrientes marinas. De igual forma, otro grupo de gente pescadora registrada en los censos y las visitas son los llamados «trujillanos», gente categorizada de forasteros que también viven de la pesca y de la convivencia con otras parcialidades indígenas a lo largo de la costa peruana. Helguero no se percata de que estas poblaciones indígenas vivían apegadas a otros principios sociales y de organización social, y que su economía de autosubsistencia se complementa con otras actividades según los calendarios climáticos y el manejo de los archipiélagos ecológicos entre las orillas del mar, la sierra y la amazonía. Esto explica porque ante este desconocimiento y/o ocultamiento, Helguero repita y reitera una retórica verbal europea con la que intentaba explicar los comportamientos distintos de esta gente frente a la economía mercantil y los patrones de vida borbónicos. Su verborrea iluminista le servirá entonces para calificar a la gente no blanca de vivir y estar llena de vicios, "reducida a una vida miserable y dolo a que se dedican». Es decir, son gentes viciosas, ladronas, tramposas (no pagan sus deudas), y que en especial, solo se dedican a extraer poca pesca para disponer de pequeñas cantidades de dinero para su uso en un tiempo corto (Helguero 1984, 62-63).

De tal forma que Helguero presenta a los pescadores indígenas como gentes que tienen muchas necesidades que satisfacer pero que vivían conformes solo con la pesca diaria, y que esto los obliga a vender sus productos como el tollo a precios arbitrarios. Se indigna en su escrito porque se trata de gentes que no tienen un sentido del "progreso», pues el tamaño de su pesca es muy pequeño y no hacen nada para acceder a medios que les permita elevar los volúmenes obtenidos.

En esta ocasión, la población de Sechura es descrita por practicar otros dos tipos de actividades laborales especializadas: los aguateros y salineros. El transporte del agua desde las orillas del río y los jaguayes lo realizan usando los hombros de los varones, las mulas y los burros, utilizando una variedad de porongos de cerámica y cruzando el despoblado desértico a 
determinadas horas. De igual forma, otro sector de la población se ha especializado en la producción y el transporte de la sal que se usa en las tinas de jabón y las fábricas de cordobanes, y también para el consumo doméstico de las familias asentadas en la ciudad de SM de Piura. En buena cuenta, se trata de dos «ramos» (aguada y salinas) en la que Helguero desconoce los volúmenes de extracción, los precios y valores corrientes; lo que sí apunta es la abundancia de ambos recursos naturales en los territorios costeros (Helguero 1984, 65).

Finalmente, otro grupo de actividades económicas registradas y practicadas por la población indígena, no las detalla Helguero porque considera que son "contingentes por la variabilidad de las gentes que los trabajan». Helguero oculta de esta forma la riqueza de la división del trabajo y de la fortaleza que mantiene el trabajo comunitario indígena que ha articulado incluso la economía mercantil y variadas herramientas y tecnologías tangibles e intangibles para conservar su patrón comunitario e identidad cultural indígena.

Helguero no tiene una idea acerca del proceso originario de formación de la socialidad humana de los indígenas de Catacaos, Sechura, Paita, Colán, Amotape, Olmos y la edificación de sus mundos en el tiempo histórico que le tocó vivir. Se trata de comunidades humanas de gente nativa y de grupos de forasteros que sobreviven temporalmente de los recursos disponibles. Desde su perspectiva de análisis lo que sí puede abordar y distinguir es la separación entre la ciudad y el campo destacando los sentidos de dos dimensiones básicas de la existencia humana: la dimensión física y la dimensión política. Pero esta última es la que oculta y rehúye permanentemente, sin embargo, entre sus apuntes no deja de anotar dispersa y fragmentariamente la continuidad de los principios de organización social impuestos por los Habsburgos, la «República de Indios» con sus bases institucionales legitimadas como la comunidad indígena, las cajas de comunidad, las cofradías, el Cabildo de Indios y las noblezas yungas.

En este escrito que prepara Helguero a comienzos del siglo XIX, encontramos cómo se encuentran profundamente articulados la economía y los principios de organización social y los procesos de reproducción social, el entretejido de una espacialidad y el manejo de la temporalidad social que servirá para delinear un tipo singular de la cualificación física y política del campo y de la ciudad. Allí nada es gratuito, los españoles refundaron la ciudad de SM de Piura como lugar intermedio y bisagra para dominar el desierto y sus médanos colocando simbólicamente iglesias con altas torres para vigilar el movimiento no solo de las recuas de arrieros que trajinaban por los caminos reales levantados por los Yngas, sino también el movimiento de las embarcaciones por el camino del mar, del Océano Pacífico llamado en ese tiempo Mar del Sur.

Don Joaquín de Helguero es un gran observador de lo que pudieron levantar las gentes originarias en medio del despoblado desértico asociadas a las autoridades ligadas al modelo y gobierno de los Austrias. Vivirá profundamente angustiado porque en el siglo XviII con las reformas borbónicas no se ha impuesto la lógica del mercado y menos la uniformización social y la cultura civilizatoria borbónica. Helguero, al recorrer por estos pueblos estacionados y dispersos en ambas márgenes del río Piura, Olmos y La Chira, encuentra que el sujeto social no ha desarrollado su autoformación individual y que todavía lo colectivo y lo comunitario tiene mucha fuerza para imponer su propia lógica a la economía indígena que labra la tierra y dedica su tiempo para autosostener a sus entidades corporativas, y que su vida está atada a la existencia colectiva de algunas instituciones, a su forma singular de socialidad y sus formas de practicar su determinación política con los corregidores, los curas y los subdelegados y las parcialidades yungas.

En este sentido, Helguero confirma un manejo singular de los espacios territoriales, pero también la particular distinción del tiempo cotidiano y el tiempo extraordinario (FEN y sequías) interaccionados con la producción, la distribución, el cambio y el consumo de una generación de la riqueza social que practican las parcialidades y los ayllus en el espacio de la socialidad de una región que abarcaba a Tumbes y Olmos a comienzos del siglo XIX.

Ahora bien, para Helguero, estos renglones menores de la producción que no quiere registrar y presentar, están representados por la producción de los sombreros (con paja mocora) en el pueblo de San Juan Bautista de Catacaos. Él apunta en su Informe que este tipo de dinámica laboral, campesina y rural, no es permanente sino estacional, y que no se realiza todos los ańos y, lo más importante, que los productos no están atados a una demanda comercial. Se fabrica «cuando los indios de aquel pueblo quieren fabricarlo». El volumen también no se ajusta a una lógica de mercado regional y encuentra que es «tan bajo el número de docenas, que 


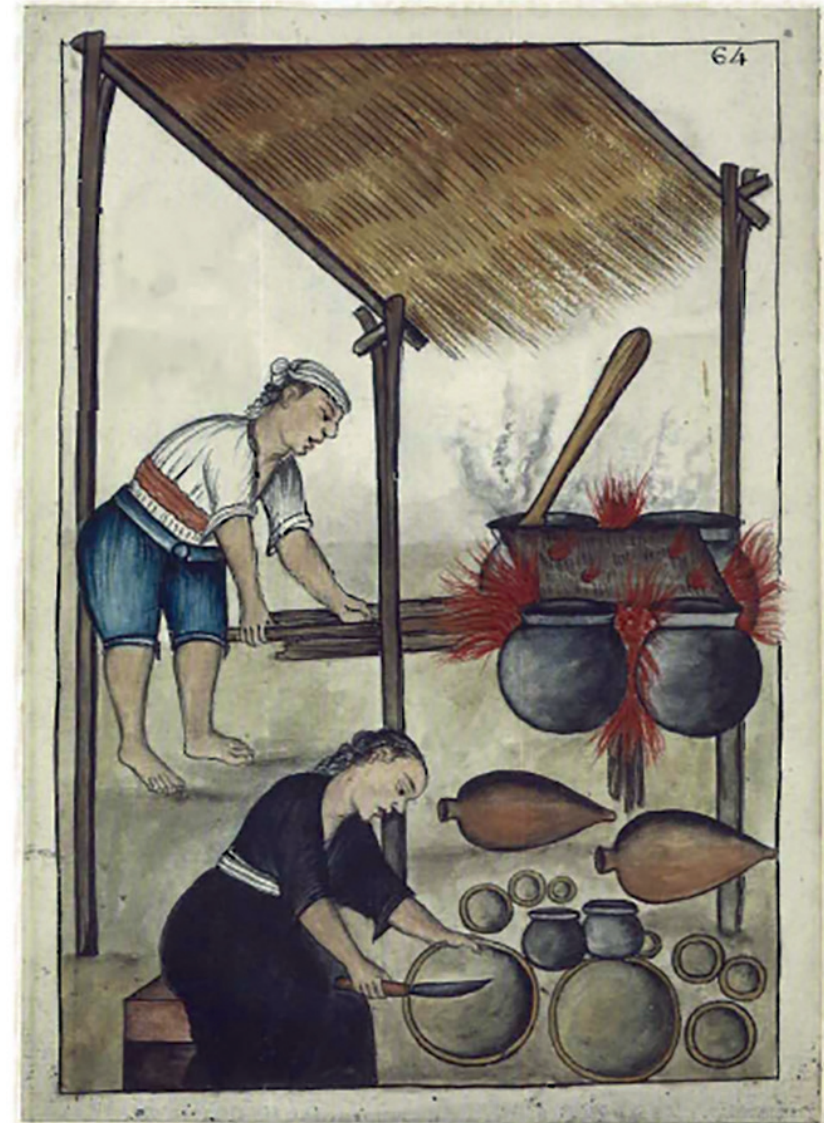

Indios cocinando chicha. Macera 2007: 166.

no se deja percibir una utilidad conocida» (Helguero 1984, 66).

Helguero no quiere aceptar que la población indígena maneja su propia visión sobre el tiempo ordinario y que las actividades económicas que realiza corresponden a otra división del tiempo del trabajo que la califica de monótona y viciosa, y que esta no sirve "para promover el giro y que progrese el comercio». $\mathrm{Su}$ preocupación se objetiva cuando registra que los pueblos indígenas también manejan un tiempo extraordinario, el de la fiesta, de las reuniones colectivas y de la práctica de una política comunal y virreinal. Los pueblos indígenas buscan vivir en armonía con la naturaleza, conservando el agua que llega del cielo y de los ríos que descienden de los Andes.

\section{Cuarto punto. "Si se hace de la provincia algún} tráfico exterior, a donde y con qué efecto, frutos o manufacturas".

Respecto al movimiento de las mercancías y al tráfico mercantil Helguero empieza de nuevo a exaltar la abundancia de los recursos naturales existentes en

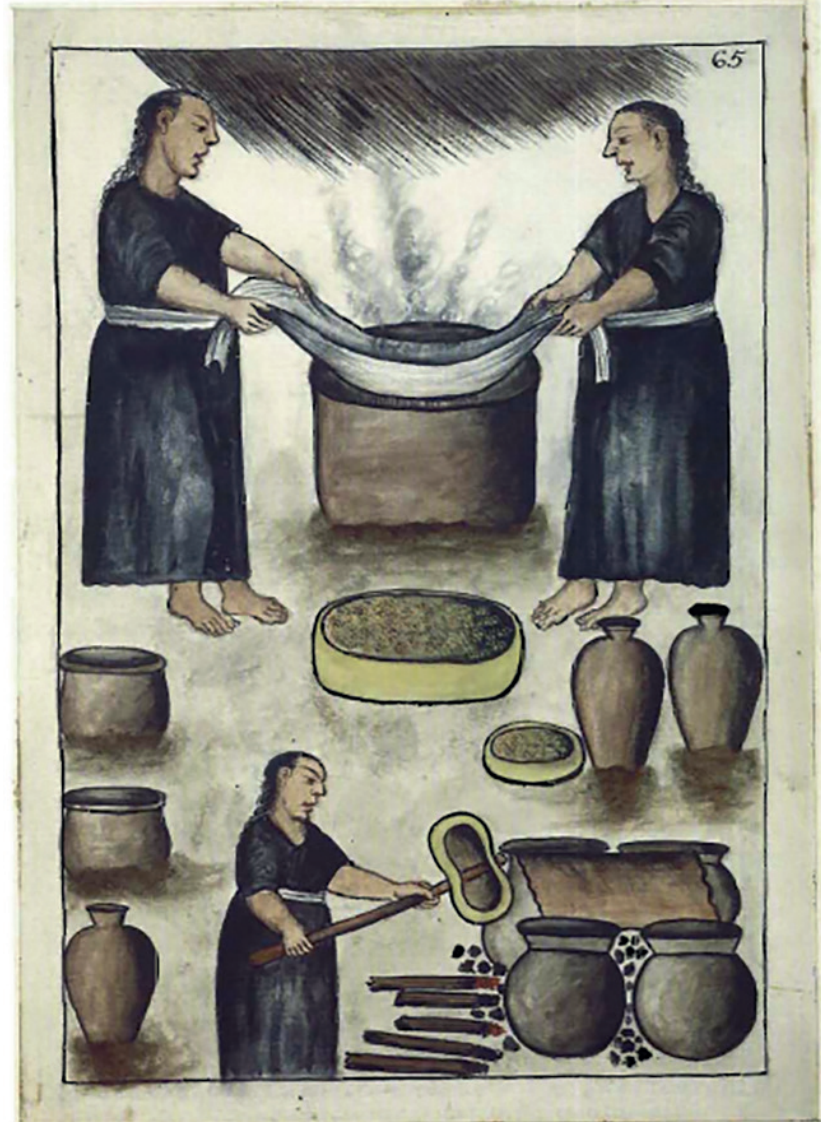

Indias cocinando la chicha. Macera 2007: 167.

los valles de Piura y a contrastarla con la formación de pequeńas microsociedades indígenas portadores de una mentalidad anormal y desviada, pues la encuentra desarticulada a la marcha que impone la civilización europea. Muestra así su desagrado planteando la falta de coincidencias con la dinámica mercantil. De tal forma que postula la tesis de que frente a una naturaleza pingüe las gentes del campo prácticamente la vuelven estéril por la «falta de adbitrio en los moradores de estas distancias" (Helguero 1984, 67). Estamos entonces frente a un registro mental portador de una visión biologista de los fenómenos sociales.

Anota que en Piura es muy pobre la actividad industrial. Respecto a la actividad de la manufactura plantea que este tipo de economía se ha dinamizado en la provincia vecina de Cuenca. Apunta que en este territorio andino sí se avanzó en la especialización de la mano de obra y en la instalación de una tecnología primaria para la transformación de la lana y el algodón. Los obrajes y chorrillos procesan y producen tejidos de tocuyos, medias y otros productos artesanales textiles usando grandes cantidades y quintales de algodón en 
rama que se traen desde los valles de Piura hacia Loja y Cuenca, villas microurbanas andinas adscritas a la Audiencia de Quito.

En esta microrregión andina, la producción textil sí es posible con la provisión de algodón en rama que se transporta desde Piura y que combinada con las lanas se verifica la producción y mercadeo de textiles que van a ser distribuidas en SM de Piura, y otros volúmenes enviados a Lima y a Chile. En este territorio, los arrieros y sus mulas transportan la producción local de pabilos, lonas y costales a un pequeño mercado interior regional. De igual forma, otros volúmenes y cargas de este tipo de textiles se dirigirán para su consumo a Panamá, y bajo la forma de hilo fino, por el contrario, se conducirá hacia el partido de Lambayeque con la finalidad de usarlo en la fabricación de colchas y una variedad de productos textiles. También postula Helguero la existencia de pequeños talleres artesanales asentados al interior de las viviendas de los yungas de Catacaos y Sechura. Precisa, de igual forma, que los tejidos finos y delicados (cumbe) todavía se producen por los grupos familiares, ofertando un escaso volumen ya que se requiere de una mano de obra especializada. Son varios grupos de indígenas que están articulados a la producción y al comercio del pabilo y de los costales, de las frazadas y las velas. En buena cuenta, una parte importante de estas familias utiliza las herramientas y los conocimientos para producir los hilados más finos y de compra segura.

La cera es otro producto manufacturado que se produce y consume en la provincia y la ciudad de Piura. Las iglesias y los pueblos rurales lo demandan para la realización de sus ciclos festivos. El resto lo venden en Cajamarca, Lambayeque, Trujillo y Lima.

De otro lado, las pieles del ganado cabrío se transformarán en cordobanes, y el sebo será utilizado para la fabricación de los jabones en las fábricas y las casa-tinas instaladas en las orillas de los ríos Piura y La Chira. Se vive un tiempo en la que los cordobanes han encontrado su mercado de consumo en Quito, Cuenca, Loja y Panamá. Otra parte de los jabones y los cordobanes serán vendidos en la ciudad de Lima.

Comparativamente, en las haciendas-trapiches de la sierra se producen azúcares y raspaduras de miel. Este último producto demanda para su procesamiento mucha cantidad de peones y sirvientes especializados y se producirá solo pequeños volúmenes. Así cuando escasea el azúcar, se trae a la sierra de Piura algunas cantidades desde Lambayeque. Helguero trata de explicar la existencia de los bajos volúmenes que alcanza la producción del azúcar, por la escasez de la mano de obra. Nada dice sobre las familias de afrodescendientes que se han trasladado, asentado y reproducido en la sierra de Ayabaca, Guancabamba y Guarmaca; los negros esclavos y libertos, no solo estarán dedicados a la crianza y a la reproducción de ganado mayor como toretes y caballos sino a la labranza y cultivo de granos como el maíz y el trigo, además del cultivo de la cańa de azúcar en las haciendas de Sondor y Tabaconas.

En este sentido, Helguero se limitará a señalar que casi toda la producción de ambos productos, azúcar y raspaduras se producirá solo en pequeños volúmenes, y asegura que una pequeña porción será remitida a Panamá y a Guayaquil (Helguero 1984, 71). Ya para este siglo, la población indígena empieza a recuperarse $y$ a reproducirse en las parcialidades cuyas gentes viven dispersas entre las quebradas y montes cordilleranos. En esta geografía de cordilleras y quebradas andinas se ha organizado una economía campesina muy fuerte al interior de las comunidades, pero también al interior de las estancias y haciendas serranas. Los grandes propietarios de tierras compran hombres y mujeres esclavos y buscan trasladar a negros, mulatos y zambos libertos para trabajar lotes de tierras en la sierra y en la montaña amazónica de Jaén de Bracamoros. En buena cuenta, una parte de la producción bajará para su venta a la provincia de Sańa y a Lambayeque. La gente de la sierra de Piura todavía vivirá combinando una economía comunitaria con la economía mercantil borbónica.

A la pregunta del Quinto punto. "¿Si abunda en la provincia algún artículo $u$ objeto comerciable, cuya extracción se halla entorpecida y convenga promover? ¿Cuál es este artículo, utilidades que promete, y medios de facilitar su giro?».

Helguero responde que existen otras producciones poco conocidas y que podrían servir para dinamizar («girar») el comercio. Seńala que los algodones de Piura son los mejores que se conocen en todo el virreinato del Perú y que aquí la manufactura textil produce tejidos delicados y estimables. Agrega que falta instalar en esta provincia una fábrica de tocuyos, y que su carencia provocaría que una parte de los capitales acumulados en algodones y lanas producidos se trasladen hacia otros pueblos ubicados en la sierra de Cuenca, un espacio andino en la que sí funciona 


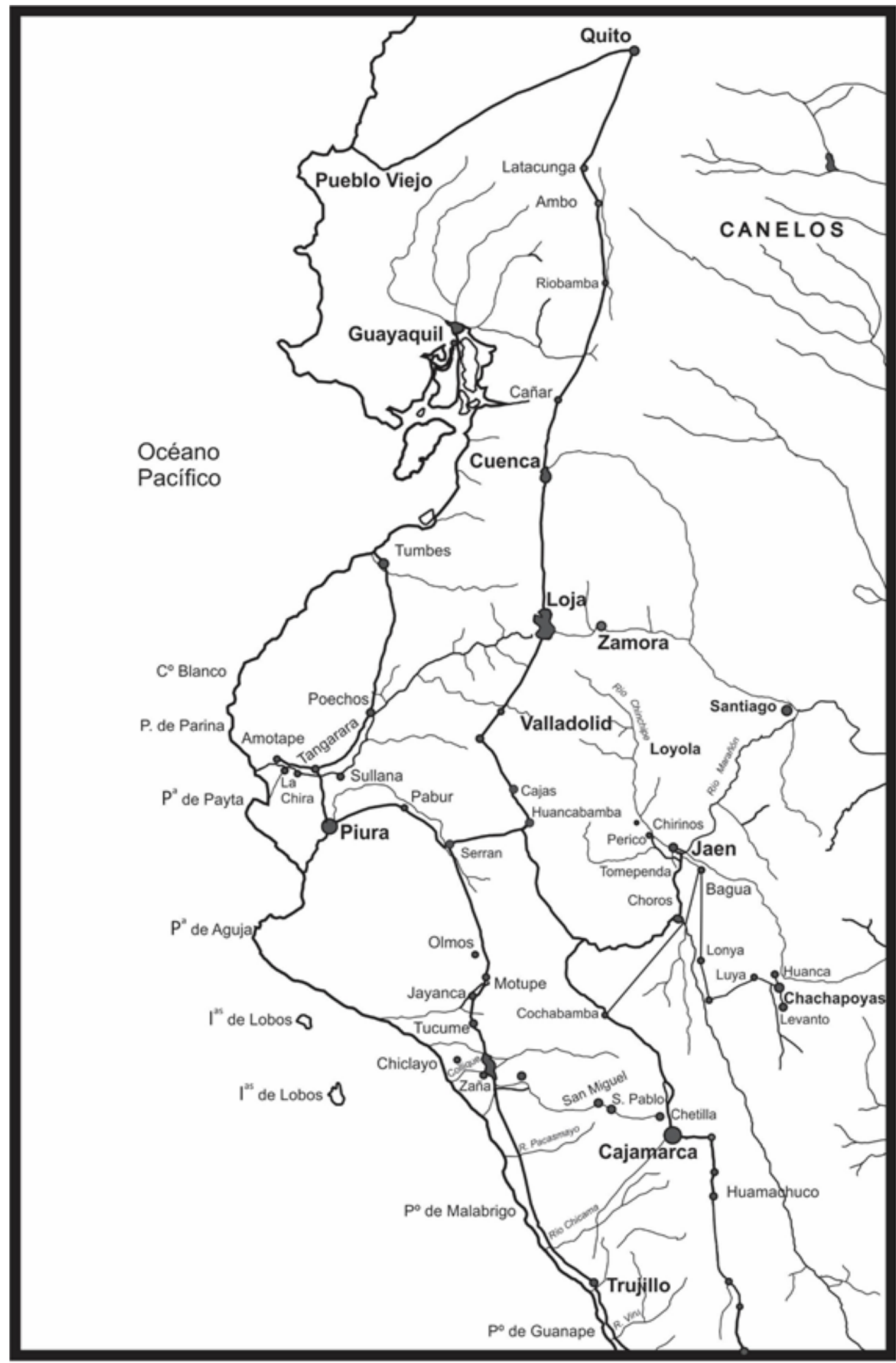

Mapa de los ríos y caminos en el Virreinato y comienzos de la República del Perú. Reelaborado por Pavel Espinoza Ortega. Fuente consultada: Hocquenghem, Anne-Marie (1994) «Los españoles en los caminos del extremo norte del Perú en 1532», en Bulletin de L'Institut Francais d'Études Andines, IFEA, Lima, Tome 23, N. ํ. 1, p. 8, Fig. 1. 
una fábrica de tejidos e hilados. Precisa que en esta provincia se utiliza el algodón cosechado en Piura y que manipulado se la mezcla con la lana para producir una diversidad de tejidos. Bajo su visión de progreso económico, Helguero realiza la propuesta de construir una fábrica en Piura y de esta forma explotar la fibra del algodón bajo la modalidad de la manufactura de textiles mucho más finos y abundantes, solo utilizando esta fibra y sin mezcla alguna. Aquí olvida precisar que son los pueblos indígenas de Catacaos, Sechura, Colán y Amotape los que disponen de un capital humano calificado y que practican el tejido e hilado desde tiempos milenarios.

Otro rubro económico que participaría de esta idea del progreso económico es la siembra de viñas en los campos piuranos para la producción de uvas y toda clase de aguardientes. Los terrenos más propicios para la siembra de los campos de la uva son aquellos que están ubicados en los contornos inmediatos a la hacienda de Yapatera. En este espacio geográfico, partido por varios afluentes del río Piura, se produce la variedad llamada Italia, Moscatel blanca y negra, un conjunto de plantas que destacan por su color, dulzura, tamaño y suavidad. Propone así incrementar las parcelas y los terrenos para ampliar la cultura y el cultivo de vińas que permitirían fomentar el comercio y la riqueza local (Helguera 1802, 75).

Una tercera planta que se cultiva en los microvalles que rodean a la ciudad de SM de Piura es el cacao. Para fomentar su crecimiento y producción propone ampliar los terrenos con la siembra de esta planta tropical. Sin embargo, se lamenta por la existencia de «muy poco espíritu para trabajar en aquello que la misma naturaleza presenta por utilidad... Ninguna labor se invierte en las vetas que se descubren en los contornos de Ayabaca, donde sin ejemplar se toma el oro en los lavaderos. No conviniéndose pues ningún vecino habitante en el Partido a un trabajo, cuya resulta efectiva, y favorable se ofrece a la vista; es de creerse la inacción para el adelantamiento de los demás objetos comerciables que merecen giro y debieran entablarse... Los medios oportunos para promover un establecimiento útil y permanente en esta provincia, son de los que depende su felicidad y reposición, y no habiendo la más leve dificultad para fijarlos en fuerza de soberanas disposiciones, y superiores órdenes, los propondré a la alta consideración de V.S.» (76-77).

Para avanzar en el progreso económico regional y en la construcción y ampliación de un mercado interno regional seńala la escasa voluntad y compromiso de los labradores criollos y de otras gentes de diferentes castas que se muestran poco sumisas para dinamizar la ampliación de las fronteras territoriales con los cultivos tropicales señalados. Reitera su planteamiento de que el progreso solo podría alcanzarse combatiendo los vicios y la vida miserable que practican las diversas castas sociales en Piura: «Este es un medio eficaz para contener el ocio de la indiada de las dos partes referidas (Catacaos y La Chira), en cuyos anexos se comprenden otros pueblos de bastante número en esta clase, y poniéndose el mayor celo en esta ocupación, se consulta darles destino a unos indios que por su misma ociosidad carecen de lo necesario, y por la misma se entrega a la revolución y vicio» (7778). Helguero está convencido de que la economía agraria provincial podría dinamizarse, y que todo esto podría ejecutarse ya que los indios se encuentran supervisados por un "patrón tributario" y sus tareas laborales están vigiladas por el gobierno de los alcaldes $\mathrm{y}$ «celadores».

Helguero recomienda una clave para que los indios de los pueblos de Paita y Sechura puedan incorporarse a la modernidad: a esta gente se les debe «refrenar la ociosidad... que los induce a la maquinación y al fraude», y que se les debe asignar también un jefe. Observa que los indígenas de estos pueblos no viven en la servidumbre sino de la libertad de cultivar sus parcelas y de labrar la tierra de comunidad autogenerándose la autosubsistencia desligada de una economía mercantil. De igual forma, los indígenas de Paita no están sometidos totalmente a la economía tributaria ya que complementariamente explotan los recursos hidrobiológicos del mar y gozan de un tiempo y ocio para movilizarse entre Guayaquil y Lima durante las estaciones climáticas anuales. Esta potencialidad económica y soberbia indígena le GEOGRAFÍA ECONÓMICA Y HUMANA DE PIURA A COMIENZOS DEL SIGLO XIX

\begin{tabular}{|l|l|l|}
\hline Valles y pueblos & Tipo de producciones & Características \\
\hline Catacaos y La Chira & Algodón en quintales y tejidos & $\begin{array}{l}\text { La gente india puede hilarlos. Los vecinos } \\
\text { deben establecer una fábrica de tocuyos }\end{array}$ \\
\hline Payta y Sechura & Pesca & Se necesita imponerles una jefatura \\
\hline
\end{tabular}




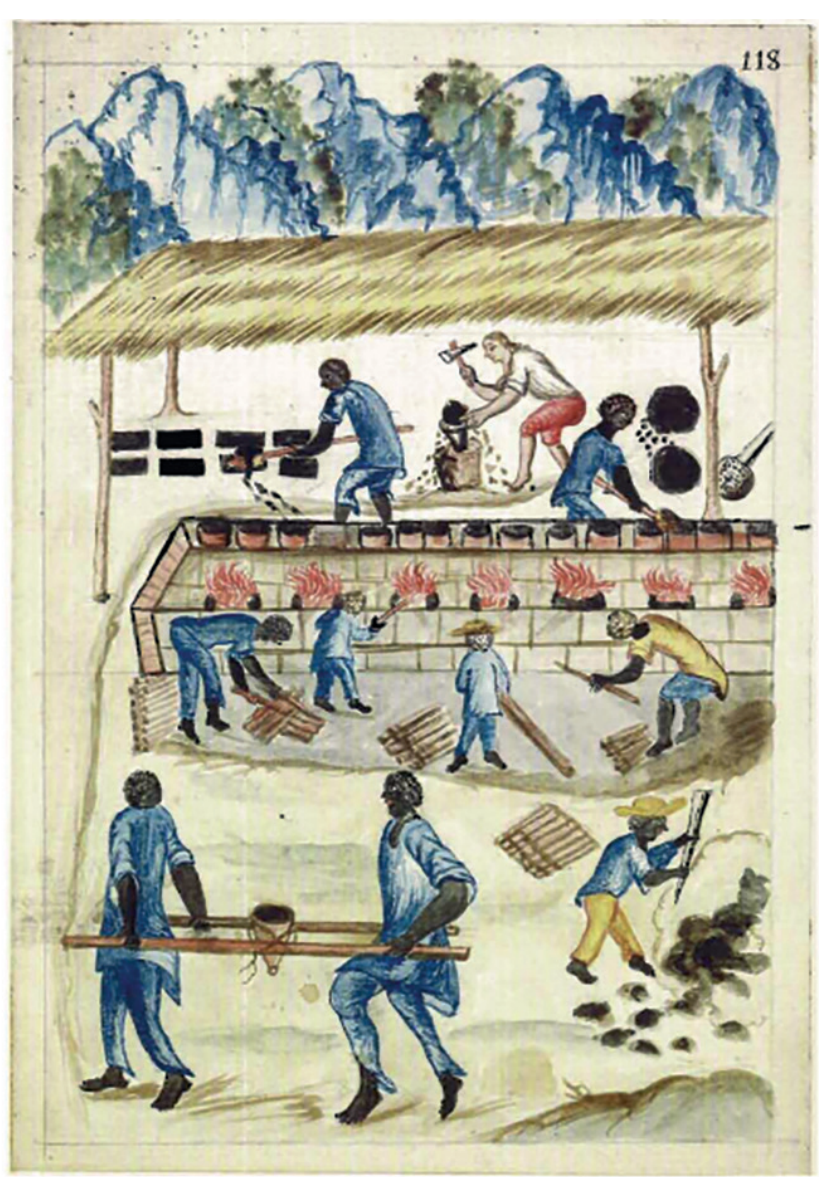

Beneficio de la brea en Amotape, Piura. Macera 2007: 162.

incomoda a Helguero, quien finalmente recomienda que solo modificándose estos patrones de conducta a la mayoría de la población podría generar mayores entradas en dinero y el progreso para las Cajas Reales.

La provincia de Piura está compuesta por la sierra y sus valles, se trata de un territorio fecundo y de variadas proporciones que permitirían lograr ventajosas utilidades y capitales. Helguero reitera su explicación acerca de la geografía humana existente que bloquea todo intento de incrementar la economía del lucro, pues la gran mayoría de la población indígena se encuentra en el «abandono y total ocio de las gentes que llegando a lo último de su ruina por el miserable estado a que los reduce este defecto perjudicial e intolerable, sufren con gusto la vida descarriada e indigente por negarse a cualquier trabajo» (79).

Observa que en Piura los hacendados son vecinos nobles pero que no disponen de mayores facultades para corregir los «excesos de sus colonos y vivientes en sus tierras y linderos», y que cada uno de ellos no responden por los crímenes que se cometen en sus respectivos lugares. Recomienda con urgencia el

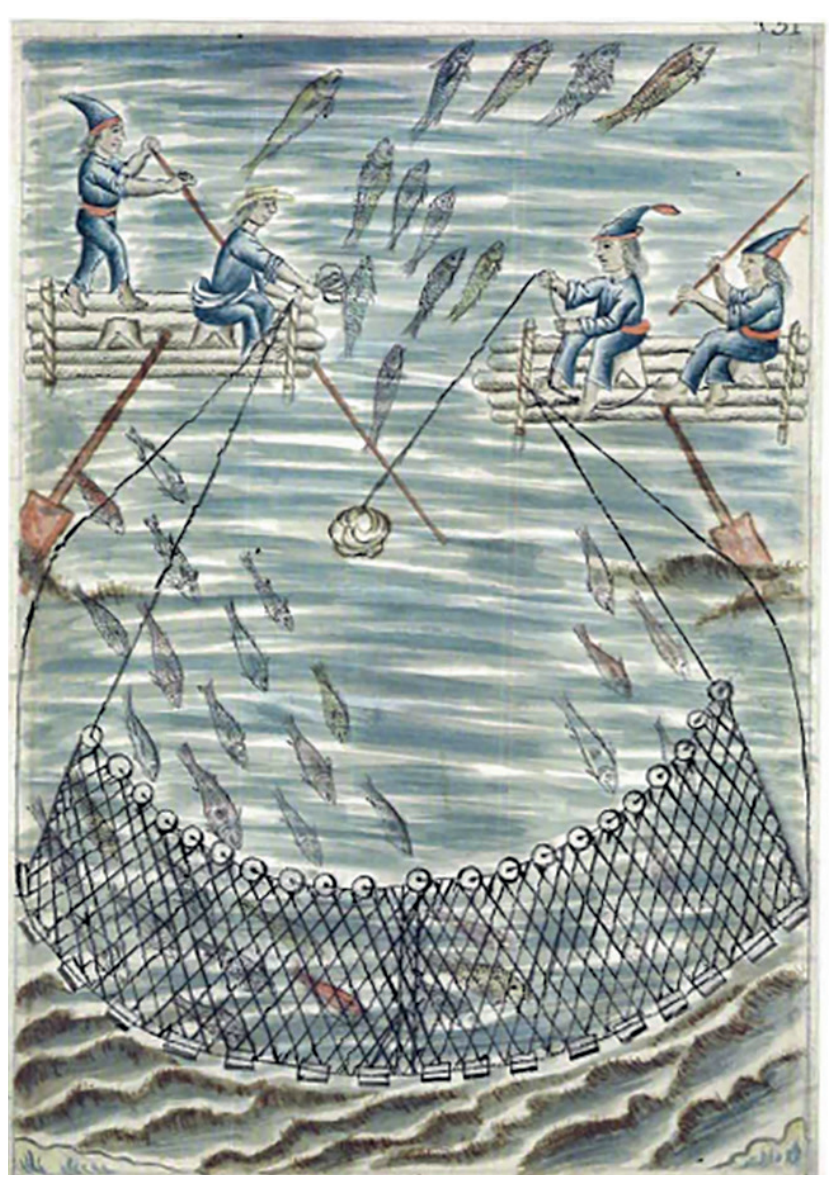

Indios pescando con chinchorro. Macera 2007: 170.

otorgamiento de varias facultades para que puedan disponer de los indios que se encuentran en los pueblos más inmediatos a sus haciendas con la finalidad de captar un número necesario y dinamizar las labores de labranza en sus tierras (80).

En suma, Helguero propone la aplicación de tres medidas que podrían ayudar a lograr la quietud social y el progreso del comercio:

1. Dividir la provincia en haciendas, pueblos y estancias, y otorgarles a los hacendados la facultad de hacer las correcciones en la movilización de los habitantes para que todos practiquen el ejercicio del trabajo.

El procedimiento técnico a utilizar sería tener a «la vista un celador inmediato que velase su conducta al cuidado de sus operaciones para corregirlas, y que no se haga ilusoria la justicia quedando impugne la culpa, a causa de que el recurso es a la ciudad, y los jueces subdelegados que carecen de ministros, olvidan la queja y por falta de auxilio, ni persiguen al delincuente ni ejemplarizan con el castigo a otros reos» (80-81). 
2. Plantea que "pudiendo el hacendado pedir a los pueblos la gente que necesita para su trabajo, y siendo obligado a contribuirla al juez del Partido, resultaría que mucha parte de los pueblos se invertiría en el público trabajo, y que de consiguiente se aseguraban fácilmente los tributos de estos indios matriculados; estarían sujetos a otra educación y gobierno. Desterrarían el ocio con la ocupación en el público trabajo, y el hacendado trabajaría con toda la extensión que sufre sus tierras, y con la misma utilidad satisfaría los justos jornales de aquellos peones, y se asentaría el comercio en todos los ramos que ofrece el dilatado terreno (81) de la provincia.

3. Propone que «si con la poca gente de que se sirve la provincia para su trabajo tiene establecido un comercio bastante y lucrativo, es necesario que habiendo en las tierras, y en las gentes proporción para cuadriplicarlo, se verificase positivamente arreglando los peones y gente a la subordinación y orden, de suerte que de este modo, y no de otro, a conocimiento del fatal estado de la provincia, pueda ella arreglarse en manera que exceda su comercio a muchos partidos del virreinato, y que su comercio sea también, en algunos renglones, bien necesario y muy provechoso a otras distancias» (82).

Helguero considera que, con la aplicación de estas reformas, de carácter administrativo y una mejor gestión en el manejo de la mano de obra, se podría lograr el progreso del comercio, y de los mismos partidos y demás lugares de la provincia.

A continuación elabora un diagnóstico sobre la ciudad y alcanza sus propuestas para lograr su progreso y la felicidad de sus gentes:

En ella no son pocos los sujetos que se destierran al campo a vivir con una mantención pobre y abandonan el comercio, por la falta de giro a causa de la ociosidad y libertinaje, y en efecto, hay hombre que logra colectar algunos efectos que adquiere por compra, como el pabilo, jabones, ropas de castilla y tierra, y deja de remitirlas por negociación a otros lugares faltando tal vez a sus contratas, perdiendo la ocasión de su mejor venta, demorándose una embarcación en el inmediato puerto de Payta y sufriendo muchas otras ocurrencias sensibles y de excesivo quebranto por una causa ridícula, cual es no hallase en tanta gente plebe un peón que trabaje por ningún dinero en enfardelar, en sacar, forrar, retobar, etc., ni alguno que se aplica por ningún caso a cualesquier maniobra de las que demanda el comercio, y ve aquí como hallándose un pobre hombre con una porción de efectos en piezas, ramas, libras, docenas, etc., sin poder arreglar su carga en número y peso, se abandona, y detesta de su giro, entregándose a la vida sedentaria, y manteniéndose con una corta siembra hasta cargarse de años, y acabar su vida, sin utilidad pública, ni privada cual debería rendir su ejercicio (83-84).

Los dueños de las recuas no pueden habilitar de mulas al cargador, porque carecen de gente para el avío de sus piaras. El resultado es que la ciudad deSM de Piura padece de una escasez de víveres, pues los propios habitantes no quieren trabajar de peones para traerlos, y también, las gentes de las haciendas y los campos tampoco quieren conducirlos. Se vive entonces un tiempo de ruina y de estancamiento para la ciudad (84-85).

Helguero busca describir la vida de los trabajadores que viven al interior de los barrios de la ciudad de San Miguel de Piura:

En ella hay cerca de 200 ranchos sostenidos de cuatro palos y cubiertos de hojas secas de árboles conocidos con el título de vichalla, para entoldar el sol que les hiciere. Estas habitaciones ocupadas por tres, cuatro o más individuos plebeyos, y por lo regular de mujeres de casta zamba o negra, que invierten el día en cocinar un alimento vasto y reducido a la carne del capado, con grasura que esta misma vierte y sazonada con una porción crecida de un ají rabioso, son a pretexto de esta mantención los albergues de toda clase. Allí concurre todo peón oficial y jornalero al principio de la mańana y con la corta cuota de un medio real, toma parte de este alimento y se embriaga con un abultado brebaje nombrado chicha, que lo rinde a la pereza, lo precipita (85) a la obscenidad, y concluye con un profundo sueño que lo aletarga. En este consume la mañana entera y al medio día, que apenas puede sostenerse a esfuerzos del reposo que antes ha tenido, repite por comida lo mismo que por almuerzo, y finaliza el día en una inacción inútil y grosera; como esto es común a toda la gente de esta clase, y hoy ha trascendido a los esclavos, y también a muchos infelices blancos que causan admiración y ternura, no se puede por esta causa servirse ni de los libres por sus jornales, ni de los esclavos por siervos (86).

En esta parte describe una variedad de experiencias laborales y sobre la vida cotidiana en Piura. Se trata 
todavía de campesinos indígenas que viven sometidos a largas jornadas de trabajo y que en sus días de descanso se reúnen en lugares apartados para consumir la chicha y el aguardiente de caña:

No hay duda, que cuando se consigue un corto número de peones, que laboree en cualesquiera faena por la mañana, trabajan hasta las doce, con exclusión de dos horas más o menos, que consumen allí mismo comiendo y bebiendo por almuerzo lo que les presentan sus mujeres, hijos y demás (87) deudos, de suerte que desde entonces se hacen incapaz por la embriaguez para el resto del trabajo hasta las doce, en que reciben precisamente el jornal de la mañana, y con él se dirigen a esas tabernas, estancos de la maldad y perdición.

Respecto a las prácticas culturales de los peones y de sus acciones, Helguero se muestra preocupado porque "Regularmente se experimentan lamentables desgracias con la repetición de muertes, heridas y pendencia, sin que pueda remediarse este exceso, de cuya tolerancia proviene hoy el estado ruinoso de la ciudad. Verdaderamente, que la experiencia visible de esta prostitución en la gente útil al trabajo demanda pronto y eficaz remedio» (87).

Helguero registra que la gente no blanca vive totalmente del consumo de la chicha y del aguardiente de cańa. Los peones de la ciudad y el campo son los mayores consumidores. Asocia la ociosidad del indio con el excesivo consumo de la chicha de maíz:

No es otro este que extinguir del todo esa abominable bebida, que produce tanto dańo, y se deja sentir aun de los transeúntes que trafican la carrera, y deseosos de constituirse en el destino a que los (87) conduce su giro, sufren con su detención los malos efectos de él, por no hallar en la ciudad un peón que rehaga sus fardos, arregle la carga, y sobre todo una recua de mulas en que partirse. Tampoco se encuentra uno, y otro auxilio en las inmediaciones del campo, porque después de la ociosidad que les es característica proviene su negativa de esa misma chicha, que tiene origen de esta ciudad, y se ha extendido a toda la provincia.

Considera Helguero que con un decreto real que pueda pregonarse en la provincia sería fácil pues quitar esta raíz del vicio para dejar expedito a la gente y no carecer de su servicio para el laboreo de la tierra, y otros tipos de servicios rurales y urbanos. Propone que solo basta una orden superior cometida a un Juez exacto, celoso y diligente lo suficiente para poder privarla, y que siempre que avive su cuidado para el efecto, castigando con severidad al ebrio y al que fomenta el vicio, y demoliendo este número abultado de tinas o botijas curtidas donde se contiene la bebida, y los tinajones o viches, donde se cocina y fermenta» (88).

A pesar de este mundo social violento de los plebeyos, Helguero considera que las gentes de Piura todavía mantienen un carácter de mucha docilidad que servirá para remediar este fatal defecto y conducta de viciosos y borrachos. Las reformas que propone servirán para alcanzar el

progreso del comercio, la quietud del lugar y la estabilidad de todos los maestros de artes que abandonan sus tiendas, oficios y familias, porque hallándose sin oficiales se entregan también a ese vicio, careciendo de los frutos de su habilidad, a la verdad apreciable por la pulidez y hermosura que demuestran sus obras; llegando a tanto extremo este desorden, que ya la ciudad no halla en ningún oficio uno que les sirva, lamentándose de esto, pero sin remedio, porque esos maestros que han aprendido en otros lugares, y que residen en este por acaso su suerte han aprendido también al vicio común que reina, (89) y no pudiendo desprenderse por la persuasión ni el interés se producen estos daños (90).

Sexto punto. "Si más de las especies de conocido y común tráfico produce la provincia algunas otras que puedan servir de primeras materias para las artes. También sales minerales, o vegetales de toda clase varia conocida por yerba de vidrio, azufres, salitres, alumbres, llamados aqui cachinas, omillos, caparrosa $y$ otros vitriolos, y todo género de yerbas, plantas, palo e ingredientes para tintas, expresión de sus criaderos, o de los lugares que los producen, sus virtudes, y uso, muestras de ellos, y precios a que se pueden conseguir».

Helguero apunta que en la provincia de Piura existen muchas minas de metales, oro y plata, en las serranías de Ayabaca. En la costa de Negritos y en territorios intermedios entre el pueblo de Sechura y el partido de Lambayeque, también existen la de azufres, alumbre y caparrosa. Informa que casi todas son desconocidas y sin laboreo actual. Todo lo contrario ocurría con las «Salinas» que los explotan en abundancia los indios de Sechura (91). 
Para el espacio geográfico de la sierra encuentra que sus gentes usan muchas yerbas y raíces medicinales: chicoria, borrajas, calaguala, escorzonera, contrayerba, chanclagua, chispicauri, llantén, berbena, perlia, moradilla, palton, culantrillo, duradilla, yerba del infante, guayusa, culen, yerba de león, yerba de culebra, espinoreal, orosus, yerba hedionda, salbarreal, yerba del toro, yerba del oso, suelda suelda, yerba del Inga, birabira, yerba del venado, arrayán y poleo.

Sobre el manejo y la manipulación, Helguero apunta que los indios son muy reservados. Los médicos-cirujanos que se encuentran en la ciudad las usan y conocen estas plantas que forman parte de un herbolario tradicional. En la ciudad de Piura existe un pequeño hospital y una botica que atiende solo a la población urbana. Confiesa que los indios son muy reservados para informar sobre los usos y los efectos en las gentes (92) por estas plantas y apunta que ha fracasado en su intento de conocer los nombres de las plantas y yerbas, los tipos de aplicaciones y las formas diversas de las curaciones.

Precisa que las que se registran en los primeros lugares de la lista de arriba las usa el «común de gentes» para tratar distintas enfermedades, fiebres malignas, costipados, picaduras de animales, tumores, hinchazones y otras más que se curan con mucho acierto. Reitera que los indios buscan ocultar el uso de estas yerbas. En resumen, anota que los nombres de estas plantas y los usos se ignoran en su mayor parte (93).

Respecto al tema y el uso de los colores se cuenta con un registro de varios "palos", como el vilco para carmelita, palo sota, palo amarillo, el carguancho, el aliso para el nácar, el nogal para el musco, la chilca para el verde, el failin para el negro, el sangurachi para el carmesí, y el azul que se forma de la tinta añil.
Para estos años de comienzos del siglo XIX, Helguero anota que en las montańas de Guancabamba y Sondor se cosecha una quina de calidad; y que en Frías esta planta sobresale y abunda la madera de cedro. Reitera también que en este caso la producción es muy escasa.

Sugiere que para que se produzca un cambio en la mentalidad económica es necesario un «orden prescripto» del virrey, de lo contrario la provincia se mantendrá en el mismo estado, en permanente deterioro, sin que pueda progresar el comercio y su giro provincial, es decir, la crisis (94).

Séptimo punto. "Precio o flete de las conducciones por mar, o tierra, de los efectos ofrutos, que se extraen de la provincia, a otras contiguas, o distantes con quienes haga su comercio".

El tráfico en la provincia de Piura se realiza por tierra a Lambayeque, Cajamarca, Trujillo y Lima. Otra ruta se dirige hacia el norte a Loja, Cuenca y Quito. Por el mar, se aprovecha los vientos y las corrientes marinas para llegar a Guayaquil, Panamá y a Lima.

Considera que estas vías y rutas de comunicación también pesan en la medición de los volúmenes y los precios de las mercancías intercambiadas. Considera que los efectos enviados para Cajamarca no «salen en derechura de esta ciudad, en consideración a que desde el (95) pueblo de Guadalupe, a 20 leguas más allá del de Lambayeque, se internan en la parte de la sierra, y desde allí toman a flete las mulas serranas de que aquí carecemos en las recuas, por cuyo motivo, sobre el flete de 20 reales a 3 pesos que cuesta la carga hasta Lambayeque, se le aumenta otro tanto de allí para Cajamarca» (96). De tal forma que en la ruta de Piura a Trujillo los precios de los fletes no son fijos ni guardan un orden. En este caso, los aranceles

\begin{tabular}{|l|l|}
\hline Ruta y transporte por el mar & Precios de los fletes \\
\hline De Piura a Lima & $5 \frac{1}{2}$ a 6 pesos por tercios dobles \\
\hline De Piura a Panamá & Las piezas menores tienen el mismo costo \\
\hline De Piura a Guayaquil & La distancia es menor y también el flete \\
\hline Ruta seguida por tierra & Aranceles y fletes cobrados por arrieros \\
\hline Piura-Lima & $\begin{array}{l}\text { Una carga con } 12 \text { arrobas a } 12 \text { pesos. En años excepcionales sube a } \\
14 \text { pesos. }\end{array}$ \\
\hline Piura- Lambayeque & Una carga a 20 reales y 3 pesos \\
\hline Piura-Trujillo & Una carga a 7 y 8 pesos \\
\hline Piura- Cajamarca & $\begin{array}{l}\text { Una carga a } 20 \text { reales y } 3 \text { pesos hasta Guadalupe y otros pesos más } \\
\text { para llegar a Cajamarca. }\end{array}$ \\
\hline Piura-Trujillo & Una carga a 8 y a 10 pesos \\
\hline
\end{tabular}


los imponen los arrieros, inflando los precios de los productos y debilitando la dinámica del comercio regional. Este es el caso de la gente india de Colán que para llevar los productos a Payta se han vueltos «tiranos en sus fletes» (97).

Octavo punto. "Derechos Reales o Municipales, pontazgos u otros gravámenes que sufren los efectos de su tráfico».

La exportación de los productos de esta provincia hacia otros lugares paga un impuesto del 6\%, a excepción de los que se embarcan en el puerto de Paita, que goza de una franquicia libre de esta contribución por una real orden. En el trayecto terrestre conocido bajo el nombre de "Carrera de Lima» que sirve para el tráfico y el transporte de productos no hay otros pontazgos ni pasajes de ríos sino en el pueblo de Jequetepeque, cerca de Lambayeque, y cerca a Trujillo, está otro llamado Chicama, Santa y el de Pativilca.

Antes de 1791 funcionaba en Jequetepeque un puente seguro y hermoso que fue arrasado por el FEN y las avenidas de aguas de este río. Las cargas en ese tiempo no pagaban ninguna contribución fiscal. En 1802, estima Helguero que se paga un "prest» para garantizar la seguridad de los arrieros y viajeros. En este caso están presentes los llamados "chimbadores», una gente especializada en "vadear» las aguas del río y asegurar los productos y la carga traída desde la provincia de Piura.

En el caso de Chicama, durante los meses de verano (febrero-marzo), crecen las aguas del río y los indios del pueblo de Santiago de Cao se dedican a transportar la carga de una a otra orilla. Finalmente, para el caso de la de Santa y Pativilca, aquí siempre rige el pago de un "prest» sobre cada carga y que se suman al flete de las mulas que usa el arriero. Este costo adicional llega de 4 a $4 \frac{1}{1} 2$ reales por el concepto de traslado de cada carga (99).

Noveno Punto. "Si hay en la provincia algunas fábricas, de qué efectos, de quienes son, y el fin a que han sido establecidas; cuanto es anualmente la extensión de sus labores, donde se consume, y lo que pueden producir cada año».

En Piura no existen fábricas para hilados y tejidos. Sobresale, en particular, la producción de tocuyos que abastece a la ciudad de Cuenca (100). Otro de los productos labrados se encuentran en la curtiembre de suelas. Para Helguero es uno de los «renglones pingues», su expansión muestra una escasez de cueros. En el espacio de los "valles» de Piura se registra una escasa mano de obra (pastores) que pueda elevar la crianza del ganado vacuno. El proyecto de instalar una fábrica tiene estas limitaciones que se convierte en una baja producción de ganado vacuno y escasez de cueros, que busca explicarlo por la «fuga que hacen los peones del trabajo» en los campos desérticos de Paita, Sechura, Pabur, Máncora, etc. (101).

Décimo punto. "Si se ha advertido, o si se teme que en el distrito de la Provincia se hace, o se puede hacer algún comercio clandestino, de qué valor anual se puede conceptuar, con qué clase de géneros, porqué puertos, radas o caletas o lugares se haga o se recele, y qué medios sean los más propios o eficaces para impedirlo y aun desterrarlo».

En este punto, la tesis de Helguero es contundente: Piura es una provincia que tiene por mar y tierra una gran proporción para la actividad del comercio clandestino. La costa marítima es muy extensa y presenta sitios de entrada para toda clase de embarcaciones marinas (102). En el puerto de Paita se realizan desembarques por toda clase de embarcaciones. De igual forma, más al sur, ocurre con Punta de Aguja el ingreso de botes o lanchas. Entre Tumbes y Sechura existe una diversidad de caletas que sirven para introducir toda clase de mercancías. Helguero apunta que el comercio del contrabando está controlado, aunque ha escuchado noticias de que se practica en pequeñas cantidades entre Paita y Lambayeque (103).

\section{A modo de conclusión preliminar}

En este trabajo buscamos valorizar la historia como patrimonio, base de identificación y de cohesión entre el individuo y la región de Piura. Helguero escribe un tipo de historia que conduce en tiempo de los Borbones y que le sirve para ampliar los horizontes de información al Consulado de Lima quienes buscan relacionar los procesos que vive la economía virreinal como parte de la colonización del reino del Perú por el sistema-mundo hispano-europeo.

Los Helguero son parte de un grupo de familias vascas que se asientan en la provincia de Piura para dedicarse a la labranza de la tierra y gozar del flujo de ganancias que ofrece el tráfico mercantil en el último 
tercio del siglo XVIII. Es un personaje singular, pues se dedica a la empresa mercantil pero también a la construcción de un pensamiento social y económico sobre la actividad agropecuaria y del algodón que oferta Piura y que a partir de la acumulación de sus capitales se dedicarán junto a otras familias a varios negocios diversificados durante ciclos de sequías y lluvias que toman la forma del FEN como la del año de 1791 que recorrió casi toda la costa del Pacífico Sur.

Este escrito de Helguera, que ahora examinamos, es una investigación de la historia económica de un espacio que ha mapeado para ofrecer una lectura de los ciclos y movimientos de la producción, los precios y salarios, pero también de un conjunto de ideas que buscan explicar por qué razones los pueblos indígenas mantienen su propio sistema productivo y tecnológico orientado hacia el autoabastecimiento regional.

De esta forma, en este escrito de Helguera encontramos un sentido fuerte de la idea de región sometido a los vaivenes mercantiles de otros espacios como Loja-Cuenca y Lambayeque por el sur del Perú. En SM de Piura se ha organizado una élite que conduce un tipo de producción cultural que asume la forma de una pequeña urbe que centraliza barrios de productores de artesanos y de cofradías, es decir, que representa una creación histórica, la formación de un espacio que labra el cuero y procesa los metales, pero también es un microespacio difusor y de asentamiento de las ideas de la libertad y la creatividad manual e intelectual.

En la respuesta a la lista de preguntas que contiene el "Cuestionario» se registra la base de un inventario de recursos que manejan las sociedades humanas, de diferentes colores de la piel, caracterizadas por su diversidad como es el algodón, la cascarilla, los jabones, los cordobanes, la caña de azúcar, las frutas, etc. Los grandes hacendados y los arrieros circulan por las montańas andinas, recorren las orillas del mar y cruzan los bosques de Pariñas y Olmos, pero también realizan jornadas fatigosas al cruzar los desiertos y las inmensidades colinas y tablazos que marca la geografía piurana y norteña. Y con la reproducción permanente de estas prácticas culturales se llegó a construir una variedad de lugares de civilización y labranza de la tierra buscando el hombre su autoemancipación de la naturaleza. Helguero reconoce y valora las diferencias regionales y mediante la pluma valora la posibilidad de encontrar la libertad económica como un fundamento de la posibilidad emancipatoria planteando por ejemplo el levantamiento de fábricas y pequeñas industrias como ya se practicaban en otras ciudades del continente americano y europeo.

\section{Referencias bibliográficas}

Aldana, Susana (1990). Empresas coloniales. Las tinas de jabón en Piura. Edic. CIPCA/IFEA, Lima.

Aldana, Susana (1992). Los comerciantes piuranos (17001830). El soporte humano de una región económica. FLACSO-Quito.

Aldana, Susana (1999). Poderes en una región de frontera: comercio y familia en el norte (Piura, 1700-1830). Edic. Panaca, Perú.

Alvarado M., Pedro (1987). Morropón. Geografia, Historia, Folklore. Lima: Editorial Euclides S.A.

Bernex de Falen, Nicole y Revesz, Bruno (1988). Atlas regional de Piura. Centro de Investigación y Promoción del Campesinado. CIPCA - Pontificia Universidad Católica del Perú. PUCP, Piura, Lima.

BLOCH, Marc (2002). La tierra y el campesinado. Agricultura y vida rural en los siglos XVII y XVIII. Editorial Crítica, Barcelona.

Bonilla, Heraclio y Christine Hünefeldt (1986). Piura: propuestas para una historia regional. Documento de trabajo No10, Serie: Historia No1, IEP, Perú.

Bosque Sendra, Joaquín (2005). «Espacio geográfico y ciencias sociales. Nuevas propuestas para el estudio del territorio». En: Investigaciones Regionales - Journal of Regional Research [en linea]: [Fecha de consulta: 24 de julio de 2017] Disponible en:<http://www.redalyc.org/ articulo.oa?id=28900610 > ISSN 1695-7253

Burga, Manuel (1993). Para qué aprender Historia en el Perú. Derrama Magisterial, Lima, Perú.

Castro-Gómez, Santiago (2005). La hybris del punto cero: ciencia, raza e ilustración en la Nueva Granada (17501816). Editorial Pontificia Universidad Javeriana, Bogotá.

Cornejo, Raúl Estuardo (2007). El alma de Piura. Elogio a un sentimiento. Lima: Editorial San Marcos.

Delavaud, Claude C. (1984). Las regiones costeñas del Perú septentrional: ocupación humana, desarrollo regional. Lima-Piura: CIPCA, PUCP.

Diez H., Alejandro (1998). Comunes y haciendas: procesos de comunalización en la sierra de Piura, siglos XIX-XX. Cusco: Edic. CIPCA, CERA Bartolomé de las Casas.

Espinoza Claudio, César (2005). «La lucha por el algodón en las tierras tropicales de Piura. La comunidad indígena 
de Catacaos y su incorporación subordinada a la economía regional colonial y republicana: XVI-XIX». En: Investigaciones Sociales, Vol. 9, Numero 14; pp. 235268; IIHS-UNMSM, Lima, Perú.

Espinoza Claudio, César (2008). «República, tierra y comunidad de indios. De las Cortes de Cádiz a Bolívar, Piura-Catacaos, siglo XIX». Investigaciones Sociales, $\mathrm{N}^{\circ}$ 21, pp. 237-268.

Espinoza Claudio, César (2013). «Historia regional e historia de la tierra: anotaciones sobre el valle de la Chira, San Lucas de Colán y Amotape, siglos XVIII-XX». En: Arqueología y Sociedad, No 26, pp. 339-368, UNMSM, Lima, Perú.

Ferrante, Bernardino y Correa, Horacio (1977). Monografía de Huarmaca. Talleres Gráficos UDEP, Piura.

Gálvez Peña, Carlos (1998). «En la frontera del reino: apuntes sobre sociedad y economía de un curato en la sierra de Piura (1780-1800)». En: Scarlett O'Phelan Yves Saint-Geours. El norte en la historia regional, siglos XVIII-XIX. IFEA-CIPCA, Piura, Perú, pp. 95-142..

Helguero, Joaquín de (1984). Informe económico de Piura, 1802. Transcrito y presentado por Nadia Carnero. Colección Historia Piurana, No 1, Edic. Cipca, SHRA, UNMSM, Piura, Perú.

Hernández García, Elizabeth (2008). La elite piurana y la Independencia del Perú: la lucha por la continuidad en la naciente República (1750-1824). IRA, UDEP, Lima, Perú.

Hernández García, Elizabeth (2011). Relaciones de poder en el Perú virreinal: el espacio piurano (siglos XVIII-XIX). Guayaquil, Ecuador: Consulado General del Perú.

Hocquenghem, Anne Marie (1998). Para vencer la muerte: Piura y Tumbes. Raíces en el bosque seco y en la selva alta - horizontes en el Pacífico y en la Amazonía Editores: Centro nacional de la investigación científica, Programa internacional de cooperación científica 125 - IFEA INCAH, Tomo 109, Perú.

Huertas, Lorenzo (1997). «Cronología y tipología de los centros poblados de la región de Piura». En: Arqueología, antropologia e historia en los Andes: homenaje a María Rostworowski. Varón Gabai, Rafael; Flores Espinosa, Javier. Edits. (Historia andina, 21), 471-486, IEP BCRP, Lima.

Jaramillo Baanante, Miguel (1998). "El comercio de la cascarilla en el norte peruano-sur ecuatoriano: evolución e impacto de una economía de exportación, 1750-1796». En O'Phelan, S., 1998, pp. 51-90.

Jensen, Holt A. (1992). Geografia. Historia y conceptos. Edic. Vicens-Vives, España.
Leguía y M., Germán (1914). Diccionario Geográfico, Histórico, Estadístico, etc. del departamento de Piura. Lima: Tipografía El Lucero.

Lequanda, Joseph Ignacio de (1793). «Descripción Geográfica del partido de Piura, perteneciente a la Intendencia de Trujillo». En: El Mercurio Peruano, Lima,vol VIII, pp. 167-229.

López J., Félix (2007). Monografía del distrito de Santo Domingo, Morropón, Piura.

Macera, Pablo (1964). «Informaciones Geográficas Coloniales». En: Revista del Archivo Nacional del Perú, tomo XXVIII, Entregas I-II, Lima, Perú.

Macera, Pablo (2000). Parlamento y sociedad en el Perú. Bases Documentales, siglo XIX. Tomo VI. Lima: Fondo Editorial del Congreso de la República del Perú.

Macera, Pablo (2014). «Razón circunstancia que don Joaquín de Helguero, Diputado del Comercio de la ciudad de Piura produce al Consulado de Lima, con relación a los Ramos de Industria de aquella provincia». Piura, 23 de noviembre de 1804; pp. 324-343. En: Miguel Pinto (compilador). Pablo Macera. Obras escogidas de Historia. Tomo I, Fondo Editorial del Congreso del Perú, Lima.

MaCERA, Pablo; Arturo Jiménez Borja e Irma Franke (2007). Trujillo del Perú. Baltazar Jaime Martinez Compañon. Acuarelas. Siglo XVIII. Fundación del Banco Continental, Lima, Perú. http://www.biblioteca.fundacionbbva.pe/ libros/libro_000049.pdf. Consultado 12/07/2017.

Maticorena, Miguel (1994). Piura. Apuntes para su geografia e Historia. CEHM, Lima.

Martínez de Compañón, Baltasar (1978 [1784]). Trujillo del Perú en el siglo XVIII. Madrid, Ediciones Cultura Hispánica del Centro Iberoamericano de Cooperación.

Moscol Urbina, Jorge Eduardo (1986). Mangachería rabiosa. Piuranidad, Piura.

Moscol Urbina, Jorge Eduardo (1991). De los Vicús al siglo XX. Piura: Cámara de Comercio de Piura.

Pinto, Miguel (Compilador) (2014 y 2015). Pablo Macera. Obras escogidas de Historia. Fondo Editorial del Congreso del Perú. Tomos I y II, Lima, Perú.

Reyes Flores, Alejandro (1999). Hacendados y comerciantes. Piura-Chachapoyas-Moyobamba-Lamas-Maynas. (17701820). Universidad Mayor de San Marcos, Lima, Perú.

Ribera Carbó, Eulalia (2005). «La geografía como disciplina científica. Por un reencuentro con la historia». En: Historias. Dirección de Estudios Históricos del Instituto Nacional de Antropología e Historia; Número 61, pp. 5366. mayo-agosto, México. http://www.estudioshistoricos. inah.gob.mx/revistaHistorias/wp-content/uploads/ historias_61_53-66.pdf. Consultado en 12.05.2017. 
Santos, Milton (2004). Por uma Geografia Nova. Da Crítica da Geografia a uma Geografia Crítica. USP, Gta. Edición, Brasil. Seminario O., Miguel Arturo (1995). Historia de Tambogrande. Una aproximación socioeconómica del medio Piura: 1532-1932. Municipalidad distrital de Tambogrande, Sullana.

Revesz, Bruno; Susana Aldana, Laura Hurtado y Jorge Requena (1997). Piura: región y sociedad. Derrotero bibliográfico para el desarrollo. Lima: CIPCACERA Bartolomé de las Casas.

Revesz, Bruno; Susana Aldana, Laura Hurtado y Jorge Requena (2013). Miradas cruzadas: politicas públicas y desarrollo regional en el Perú. CIPCA-IEP, Lima, Perú.

Revesz, Bruno y Oliden, Julio (2011). Piura: transformación del territorio regional. SEPIA XIV. CIPCA, Lima, Perú.

\section{Anexo I. Cuestionario enviado por el Tribunal de Consulado de Lima}

Punto dos. Producciones de toda clase que se cosechan en este territorio con designación prudente del monto anual de cada una.

Tercer punto. Precios corrientes de estas producciones, y demás objetos comerciables de la provincia.

Cuarto punto. Si se hace de la provincia algún tráfico exterior, a donde y con qué efecto, frutos o manufacturas.

Quinto punto. ¿̨i abunda en la provincia algún artículo u objeto comerciable, cuya extracción se halla entorpecida y convenga promover? ¿Cuál es este artículo, utilidades que promete, y medios de facilitar su giro?

Séptimo punto. Precio o flete de las conducciones por mar, o tierra, de los efectos o frutos, que se extraen de la provincia, a otras contiguas, o distantes con quienes haga su comercio.
Octavo punto. Derechos Reales o Municipales, pontazgos u otros gravámenes que sufren los efectos de su tráfico.

Noveno punto. Si hay en la provincia algunas fábricas, de qué efectos, de quienes son, y el fin a que han sido establecidas; cuanto es anualmente la extensión de sus labores, donde se consume, y lo que pueden producir cada año.

Décimo punto. Si se ha advertido, o si se teme que en el distrito de la Provincia se hace, o se puede hacer algún comercio clandestino, de qué valor anual se puede conceptuar, con qué clase de géneros, porqué puertos, radas o caletas o lugares se haga o se recele, y qué medios sean los más propios o eficaces para impedirlo y aun desterrarlo. 